\title{
Task-Based Language Teaching (TBLT): A Vietnamese Case Study Using Narrative Frames to Elicit Teachers' Beliefs
}

\author{
Roger Barnard \\ University of Waikato, New Zealand \\ rbarnard@waikato.ac.nz \\ Nguyen Gia Viet \\ Ha Tinh University, Vietnam \\ University of Waikato, New Zealand \\ viet.nguyengia@htu.edu.vn
}

\begin{abstract}
Like many other methodological innovations, Task-Based Language Teaching (TBLT) has been applied to many English language curriculums across Asia. However, little research has been done to explore what teachers know and believe about these reforms in their specific contexts. This paper derives from an in-depth study of teacher cognition in Vietnamese high schools using multi-methods of data collection. It will present and discuss findings from one of the methods used to elicit teachers' knowledge and attitudes - 'narrative frames' (Barkhuizen \& Wette, 2008). Specifically, teachers were asked to write (in Vietnamese) reflective comments about their attitudes towards TBLT, and their recent experience of applying it in their classroom. After presenting some of the findings, the application and usefulness of this approach to data collection in relatable contexts will be considered.
\end{abstract}

Two versions of curricular innovation have been identified: the intended reform, which presents idealised prescriptions, and the realised version, which is actually implemented in classrooms (Coleman, 1996; Fullan, 1993; Markee, 1997). There is often a gap between the two because the experience and perceptions of the key decision-makers - the teachers - are usually not taken into account (MacDonald, 1991; McGee, 1997). This paper reports an aspect of an in-depth case study into the beliefs and practices of a group of Vietnamese teachers in regard to the innovative national curriculum in Vietnamese high schools in which Communicative Language Teaching (CLT) and Task-Based Language Teaching (TBLT) are fundamental features. The paper will focus on the initial phases of data collection in the research project, in which teachers were asked to complete narrative frames (Barkhuizen \& Wette, 2008) and thereby reflect upon their attitudes and experiences of using the new curriculum materials in their classes. Extracts from these narratives will be presented and briefly discussed to bring out the extent of convergence and divergence from their understanding of communicative language teaching and their reported classroom practices. The paper will conclude with a discussion of the methodological issues of this approach to eliciting teachers' beliefs and attitudes.

Language Education in Asia, 2010, 1(1), 77-86. http://dx.doi.org/10.5746/LEiA/10/V1/A07/Barnard_Nguyen 


\section{Task-Based Language Teaching in Vietnam}

TBLT is based on communicative and interactive tasks which require meaningful communication and interaction among learners (Nunan, 2004; Bygate, Skehan, \& Swain, 2001). In doing such tasks, learners acquire grammar implicitly, and the need for explicit grammar teaching is discounted. CLT has been espoused as the guiding principle of many national curricula in Asian school systems, as elsewhere. However, in his review of practices in six Asian countries, Nunan (2003, p. 606) argues that "rhetoric rather than reality is the order of the day." This view is endorsed by Littlewood's (2007) overview of task-based learning in many Asian contexts: he reports a great mismatch between the tenets of CLT/TBLT and local cultures of learning. These views are supported by many empirical case studies, such as those in Hong Kong (Carless, 2003, 2007), China (Wang, 2008; Hu, 2002), Korea (Yoon, 2004; Jeon \& Hanh, 2006). Japan (Nishino \& Watanabe, 2008; Sato, 2002), and Thailand (Nonkukhetkhong, Baldauf, \& Moni, 2006; Segovia \& Hardison, 2009; Tayjasanant \& Barnard, 2010).

As reported in Canh and Barnard (2009, p. 23), the newly documented English language curriculum in Vietnamese high schools (Ministry of Education and Training [MOET], 2006) aims to enable school pupils to have basic communicative competence in all four skills, as well as a formal knowledge of English and an appreciation of the cultures of English-speaking countries. In addition, this document states that "communicative skills are the goal of the teaching of English at the secondary school while formal knowledge of the language serves as the means to the end" (MOET, 2006, p. 6). The national English curriculum is effectively operationalised in a locally-written set of textbooks, which, according to the authors (Van, Hoa, Loc, Loi, Minh, \& Tuan, 2006), adopt communicative learner-centred approaches. Teachers are expected to organise classroom activities so that students can engage with each other "actively, creatively and cooperatively" (Van et al, 2006, p. 10) through individual, pair, and group work in meaningful interaction within a task-based framework.

However, a number of Vietnamese educators questioned whether the school system and its teachers were ready for such a radical change from more traditional methods and approaches. For example, Pham (2000, p. 23) argued that "modern teaching methods should be applied with a close and careful consideration of the cultural values of Vietnam." Another applied linguist suggested that a lack of appropriate professional development meant that "teachers are generally incapable of teaching English communicatively in their real-world classrooms" (Canh, 2002, p. 33). Tomlinson and Bao (2004) conducted a survey with teachers and found that many did not wish to change their methods. To a large extent, this unwillingness may be due to the strong washback effect of the national examinations, in which the skills of speaking and listening are not tested and only multiple-choice tests are used to assess grammatical and vocabulary accuracy (Canh \& Barnard, 2009).

\section{Implications for Research}

Before an "intended" curriculum can be fully realised, it is necessary to take into account the values and beliefs of the teachers concerned, as these are the executive decision-makers who will actually implement the curriculum. Unless this is done, a curricular innovation is likely to fail, or at least have its aims subverted. Many years ago, it was realised that "it is obvious that what teachers do is directed in no small measure by what they think" (National Institute of Education, 1975, p. 1), and that teaching is "substantially influenced and even determined by teachers' underlying thinking" (Clark \& Peterson, 1986, p. 255). More recently Borg (2006) has conducted a meta-review of empirical studies of language teachers' beliefs and found, for example, that among the 38 studies he considered concerning grammar, most of the teachers surveyed or interviewed placed a great emphasis on the importance of the explicit instruction 
of grammar - in contrast to the implicit strategies required in 'strong' CLT methods such as TBLT. Borg $(2006,2009)$ stressed the need for more research into language teachers' beliefs and practices in terms both of geographical settings (most of the studies he reviewed in 2006 were conducted in Europe or North America) and diverse educational settings, such as schools where teachers are faced with large classes and perhaps cultures of learning which differ from those in which the principles and procedures of CLT have been developed. It is this research space that the present study wishes to occupy by illustrating how teachers' beliefs can be elicited through the use of narrative frames (Barkhuizen \& Wette, 2008).

There are many approaches to collecting data relating to teachers' knowledge, beliefs and experiences, one of which is narrative inquiry. This approach to research aims to understand the experiences of people in the particular contexts in which they live and work (Connelly \& Clandinin, 1990; Clandinin \& Connelly, 2000), and involves eliciting and documenting a story or collection of stories (Murray, 2009). Cortazzi (1993) suggested three trends in professional teacher development have given considerable impetus to representing teachers' voices through narrative inquiry: firstly, an increased attention to teacher reflection; secondly, more emphasis on teacher knowledge; and thirdly, an increase towards empowerment of teachers in professional development programmes. By asking language teachers to tell stories of their personal experience, this research project sought to explore what they think and why they think in that way, and in doing so, it is hoped that the lives of both researchers and participants are enriched (Creswell, 2005).

According to Barkhuizen and Wette (2008, p. 375, italics in original):

The concept of narrative frames is based on a similar concept in the field of writing education. Writing frames are used to provide a "skeleton to scaffold writing" (Warwick \& Maloch, 2003, p. 59). They are comprised of a template of "starters, connectives and sentence modifiers which give children a structure within which they can concentrate on communicating what they want to say whilst scaffolding them in the use of a particular generic form" (Wray \& Lewis, 1997, p. 122).

A narrative frame is similar to a semi-structured interview, which allows the participant to expand upon the points posed by the researcher. However, participants have more freedom to divulge information in frames than may be possible in an interview, where avoiding or sidestepping potentially face-threatening questions can be difficult. Moreover, unlike conventional interviews, completing these frames in their own time and place allows participants to reflect more fully on issues. In the present study, it should be noted that narrative frames were followed up by individual face-to-face interviews, with the intention of combining the advantages of both; the emerging information was subsequently triangulated with data from other procedures. The decision to use Vietnamese in all these interactions was crucial because - even though the participants were teachers of English - it was considered that using their first, rather than a second, language would enable the participants to express themselves more thoughtfully and clearly and would be probably less threatening and easier for them to do so. This latter point is extremely important, as this was the first time that the participants had been asked to carry out a task of this nature.

\section{The Present Study}

The wider research project, a part of which this paper reports, explored the extent of convergence between teachers' beliefs about TBLT and their classroom practice. The project began with a short series of interactive professional development workshops which covered the 
principles of TBLT, exemplification and discussion of task types, and the adaptation and planning of textbook tasks. The wider study adopted a multimethod approach to data collection involving the following: the elicitation of the teachers' beliefs and their reported practices via narrative frames, audio-recorded group-lesson planning, and observation of these planned lessons, followed immediately by stimulated recall sessions with the observed teachers and focus group discussions with the teachers in each of the schools. Narrative frames were used in the first stage of the project's data collection process, and were much believed to provide useful initial information for shaping and adjusting later methods of data collection. The 23 participants included 19 female and 4 male graduates ranging in age from 25 to 40 years; all of them hold BA degrees. Their teaching experience ranged from two to thirteen years, and they worked in three urban high schools. They were asked to write three openended frames. Each frame was distributed at the end of each workshop session, and participants were instructed to complete the frame in as much detail as possible in their own time, and to bring it back the following session. The following is an English translation of example frames:

1. In my opinion, to learn English well, students need to be provided with Therefore, teachers need to always

The success of an English lesson is much subject to

because

2. I think students (need/need not) to master grammar rules, because

Therefore, the most important thing in learning on the part of students is

3. A lesson that I recently taught was a

(reading/writing/listening/speaking/grammar) lesson.

The topic of the lesson was

The lesson required students to

The most successful part of the lesson was

However, I noticed students had difficulty in

I solved the problem by

The lesson could have been better if

The narrative frames were subjected to the constant comparative methods of grounded analysis (Charmaz, 2006). The first step was to read all the narratives to compare and contrast the points within them; this was done by coding the data with labels or names for particular ideas or events that emerged and re-emerged across the frames. Following this, connections between the codes were identified and these links were grouped into categories and themes "to uncover the commonalities that exist across the stories that make up a study's database" (Polkinghorne, 1995, p. 14).

For the sake of brevity, only a few of the teachers' written comments are presented below, and readers are invited to contact the authors if they would like further details.

\section{Personal Approaches to Language Teaching}

\section{Findings: Some Examples}

Most teachers identified the importance of creating communicative activities, for example, "the lessons must be interesting, real-life related, non-pressure, dynamic and effective" (Teacher 1), and "if the teacher inserts into the lesson effective communicative activities, he will help students not only learn the language, but also use the language in real life" (Teacher 3). 
Teachers also stressed their role in motivating students as well as the importance of the relationship between motivation and communicative activities:

In my opinion, to learn English well, students need to be provided with motivation and desire to learn English. At the same time, they need to have environment and time to practice language skills. Therefore, teachers need to always create communicative activities alongside with language exercises to motivate students. (Teacher 5)

\section{Attitudes Towards Form-Focused Instruction}

Although these teachers espoused the principles of communicative language learning, the majority also identified the importance of providing students with explicit knowledge of grammar. In Part 2 of the frames, many of the teachers agreed with Teacher 7, who stated that "students need to master grammar rules" because "not knowing grammar will result in incorrect communicative goals" (Teacher 3 ), grammar rules "are the basics for skills" (Teacher 5) and "help them (i.e., students) be confident in communication" (Teacher 11). Only one teacher downplayed the importance of grammar: "I think students need not master grammar rules, because they are not the deciding factor of communication" (Teacher 6). Even in a skills lesson, as shown in the section below, teachers also revealed the role of explicit grammar in their stories.

\section{Personal Narrative of a Successful Lesson}

Teachers' stories, mainly from Part 3, revealed a number of themes, some of which are reported below.

Perceptions of the successful part of a lesson. According to the teachers' stories, what was successful in a lesson was quite procedural, rather than practical. For them, in a skills lesson, students understanding how to do tasks (Teacher 18), being able to tell differences between types of conditionals (Teacher 19), or understanding what the teacher explained (Teacher 8) are examples of the most successful part in a lesson.

Perceptions of students' difficulty. The majority of teachers perceived that students generally had problems with communication tasks. They indicated that students had difficulty in expressing their ideas in full sentences. Teachers said that the reason for this was the lack of knowledge in grammar and vocabulary. For example, one teacher said:

I noticed students had difficulty in expressing meaning in sentences, because they usually made mistakes in pronunciation, vocabulary and grammar structures. (Teacher 10)

One teacher reported that language distance was the reason for students having difficulty:

I noticed students had difficulty in using prepositions, because the way Vietnamese use prepositions is not totally the same as English do. (Teacher 12)

Even Teacher 6, who felt that it was not necessary for students to master grammar rules, reported that in a speaking lesson:

I noticed students had difficulty in finding words and structures to express meaning, because they lack vocabulary of this area, and they mainly read out answers from a piece of paper. (Teacher 6) 


\section{Summary of Findings}

These teachers' personal approaches and attitudes towards grammar teaching and their stories appear to be contradictory. In other words, there is a certain divergence between their understanding of communicative language teaching and their reported classroom practices. They wrote that communicative activities play an important role in motivating students to learn. However, their attitudes and stories reveal their strong beliefs in the value of explicit form-focused instruction; most of them emphasised the role of grammar in language use and the need for their students to produce language correctly in terms of grammar, vocabulary, and pronunciation. In this respect, their reports may be perceived as merely paying lip service to CLT (Hu, 2002), and a divergence to TBLT principles (e.g., Nunan, 2004; Littlewood, 2004; Ellis, 2003) can be interpreted from their reported approaches and stories, but it is more likely that these teachers are faced with the problems of realising an ambitious curriculum for which they had not been adequately trained. In this respect, their views, similar to those in the published research cited earlier in this paper, reflect their inability to implement the intended curriculum. What is important about this study, and different from the many surveys which have been carried out into teachers' attitudes, is that the participants' voices can be clearly represented through these narrative frames. It is hoped that teacher-researchers in other contexts will consider using this elicitation device, and some methodological implications are discussed below to facilitate this possibility.

\section{Discussion: Methodological Implications}

The adoption of these frames in the Vietnamese context presents implications in terms of how to administer them, ethical issues, and points about analyzing the data.

In terms of administration, there are a number of important factors that needed to be considered. First of all, to ensure a maximum rate of return, the frames were delivered and collected during the workshops by the researcher. (There were a few occasions when some respondents had to be reminded to bring them to the session.) Secondly, it was decided to divide the frames into separate parts, each to be completed before starting the next one; this broke down the task into manageable portions, thus reducing the task burden at any one time. Thirdly, the participants were encouraged to read through each part of the particular frame before beginning any written response, and to ask questions for clarification (Barkhuizen \& Wette, 2008). They were urged to reflect upon their own beliefs and experience based upon their personal knowledge; participants' questions such as "What do you want me to say?" had to be treated very tactfully. It is readily acknowledged that the data provided by these frames presents the same potential threats to reliability as any other self-report method, however rigorously and consistently the procedures of data collection and analysis are carried out and however transparently and honestly the findings are reported. This is particularly the case as regards the truth value of what the participants say about their experiences and perceptions. It may be that the participants are not consciously aware of aspects of their own activity. Consequently they may unwittingly provide misleading data or simply fail to provide necessary information. Even when they are fully cognizant and actively participating in the research project, they may not be willing to disclose their knowledge to others. Such unwillingness might arise for various reasons, among them the perceived threat to their personal or professional positions from accidental - or deliberate! - breaches of confidentiality.

This raises the issue of ethical propriety. It is, of course, essential in any research involving human subjects that the potential participants be fully informed about the purpose of the research activity. As Morrison (1998, p. 186) has noted, "despite assurances that the work is 'academic' one is never quite sure that the explanation is accepted." Therefore, in order to avoid any suspicion of "hidden agendas," all questions or concerns on the part of the potential 
participants were encouraged and fully addressed. On the basis of this information, the teachers were then asked to consent to participate and they were made aware that they could withdraw their participation at any time, with no need to give any reason. In this case, as is now conventional in university-sponsored research, this consent was given in written form. It is also strictly required that the data provided by the participant should be treated in confidence and his/her privacy be safeguarded. In the case of narrative frames, this may present a dilemma to the researchers. If the participants can be assured that their privacy can be entirely guaranteed because each narrative will be completed anonymously, and thus no one will know who has written what, then they are likely to write more fully and freely, and perhaps (self) critically. However, anonymous reports would not enable the researchers to follow up on specific points made in the individual narratives in subsequent phases of the project. In the present case, it was decided that the participants should be invited to write their names on each frame, after being assured that only the researchers would know the identity of the writer and would not in any circumstances divulge the actual sources of any information thus derived. (This is why the names of the narrators presented above are not given.) In this sense, the privacy of the individuals was in fact revealed (to the researchers) but their confidentiality was ensured. This does not altogether resolve the issue of truth value, but there is sufficient internal evidence among the narratives to suggest that the writers were being as honest as possible. The extent that this is so is due to the relationship of academic and professional trust that was built up during the workshop sessions and thereafter.

In our study, the fact that the participants completed the frames in stages meant that the researchers were able to go back to individuals for further clarification or additional comments on particular issues. Had there been a much larger number of participants, as was the case in Barkhuizen and Wette's (2008) study, it might have been appropriate to create a composite picture of "the teacher" by drawing on the common themes identified. However, as there were only a few participants in this study, and many of them would participate in the later phases of the project, the information thus collected served as a useful platform to triangulate data gathered during semi-structured interviews, classroom observations, and focus group sessions. The implication is that with small numbers of participants, narrative frames can more usefully complement other data than serve as the main, or only, source of information.

\section{Conclusion}

Researchers applying narrative forms of data collection have commented on the advantages this approach presents. For example, both Creswell (2005) and Murray (2009) point to the opportunity that narratives offer for personal experiences in actual school settings to be made accessible, and teachers' voices heard. Creswell also points to the possibility that researchers and participants may establish mutual trust, which should help to reduce the perception that teaching and research are separate activities. Pavlenko (2007) regards narratives as accessible, aesthetically interesting, and - because of the reflection involved - empowering to the participants. With regard to using frames to guide narratives, Barkhuizen and Wette (2008) point out that the structured nature of the data makes for easier analysis than if the stories were entirely free-flowing.

There are, however, some limitations, both in general and in this particular study. First of all, compared to conventional questionnaires and interviews, writing narratives (even in their first language) may be an unfamiliar procedure for the participants; in the present study, some of the teachers' first attempts were short, tentative and, frankly, somewhat unreflective; however as they gained both familiarity and confidence in the procedure, they wrote at more length and more easily and critically. Some teachers also felt constrained by having to write within a frame, which they sometimes felt might not allow them to express their ideas fully; as noted 
above, they were encouraged to write beyond the set boundaries if they wished to. Another limitation in this study is the limited number of participants, which means that it is not possible to generalise beyond the actual case histories. Moreover, as previously indicated, the issue inevitably arises of truth value of what the participants wrote, and in the present case there were opportunities to triangulate the narratives with other sources of data. Finally, this was the first time that either the authors or the participants had applied Barkhuisen and Wette's (2008) narrative frames. It was, therefore, for us - as well as the participants - a learning experience.

We are sure that, when we use narrative frames again, to improve our practice, we will apply the lessons learned from this first attempt. In spite of the various constraints and limitations, we feel that we have obtained some useful data and in doing so we have understood more about our participants and how to better elicit valuable data from them. We therefore recommend other teacher-researchers to consider adopting this method of data collection, among others, when exploring the complex world of language teaching.

\section{Biodata}

Roger Barnard teaches applied linguistics. In Europe and the Middle East, he was a teacher trainer, curriculum developer, and adviser to education ministries. His research interests include the linguistic development of bilingual children and the beliefs and practices of language teachers. His latest book is Creating Classroom Communities of Learning.

Nguyen Gia Viet has been an English language teacher since 1997 and and recently a teacher trainer for a number of years in Ha Tinh Province, Vietnam. He is currently a Ph.D student at the University of Waikato, New Zealand. His research focuses on language teacher cognition and task-based language teaching.

\section{References}

Barkhuizen, G., \& Wette, R. (2008). Narrative frames for investigating the experiences of language teachers. System, 36(3), 372-387. http://dx.doi.org/10.1016/j.system.2008.02.002

Borg, S. (2006). Teacher cognition and language education: Research and practice. London, England: Continuum.

Borg, S. (2009). Language teacher cognition. In A. Burns \& J. C. Richards (Eds.), The Cambridge guide to second language teacher education (pp.163-171). Cambridge, England: Cambridge University Press.

Bygate, M., Skehan, P., \& Swain, M. (Eds.). (2001). Researching pedagogic tasks: Second language learning, teaching, and testing. London, England: Longman.

Canh, L.V. (2002). Sustainable professional development of EFL teachers in Vietnam. Teacher's Edition, 10, 32-37.

Canh, L.V., \& Barnard, R. (2009). Curricular innovation behind closed classroom doors: A Vietnam case study. Prospect, 24(2), 20-33.

Carless, D. (2003). Factors in the implementation of task-based teaching in primary schools. System, 31(4), 485-500. http://dx.doi.org/10.1016/j.system.2003.03.002

Carless, D. (2007). The suitability of task-based approaches for secondary schools: Perspectives from Hong Kong. System, 35(4), 595-608. http://dx.doi.org/10.1016/j.system.2007.09.003

Charmaz, K. (2006). Constructing grounded theory: A practical guide through qualitative analysis. Thousand Oaks, CA: Sage.

Clandinin, D.J., \& Connelly, F.M.(2000). Narrative inquiry: Experience and story in qualitative research. San Francisco, CA: Jossey-Bass. 
Clark, C. M., \& Peterson, P. L. (1986). Teachers' thought processes. In M. C. Wittrock (Ed.), Handbook of research and teaching ( $3^{\text {rd }}$ ed.) (pp. 255-296). New York, NY: Macmillan.

Coleman, H. (1996). Society and the language classroom. Cambridge, England: Cambridge University Press.

Connelly, F. M., \& Clandinin, D. J. (1990). Stories of experience and narrative inquiry. Educational Researcher, 19(5), 2-14. http://dx.doi.org/10.3102/0013189X019005002

Cortazzi, M. (1993). Narrative analysis. London, England: Falmer Press.

Creswell, J. W. (2005). Educational research: Planning, conducting, and evaluating quantitative and qualitative research ( $2^{\text {nd }}$ ed.). Upper Saddle River, NJ: Pearson Education.

Ellis, R. (2003). Task-based language teaching and learning. Oxford, England: Oxford University Press.

Fullan, M. (1993). Change forces: Probing the depths of educational reform. London, England: Falmer Press.

Hu, G. (2002). Potential cultural resistance to pedagogical imports: The case of communicative language teaching in China. Language, Culture and Curriculum, 15(2), 93-105. http://dx.doi.org/10.1080/07908310208666636

Jeon, I., \& Hahn, J. (2006). Exploring EFL teachers' perceptions of task-based language teaching: A case study of Korean secondary school classroom practice. Retrieved from http://www.asian-efl-journal.com/March06_ijj\&jwh.pdf

Littlewood, W. (2004). The task-based approach: Some questions and suggestions. ELT Journal, 58(4), 319. http://dx.doi.org/10.1093/elt/58.4.319

Littlewood, W. (2007). Communicative and task-based language teaching in East Asian classrooms. Language Teaching, 40, 243-249. http://dx.doi.org/10.1017/S0261444807004363

MacDonald, B. (1991). Introduction. In J. Rudduck (Ed.), Innovation and change (pp.1-7). Milton Keynes, England: Open University.

Markee, N. (1997). Managing curricular innovation. Cambridge, England: Cambridge University Press.

McGee, C. (1997). Teachers and curriculum decision-making. Palmerston North, New Zealand: The Dunmore Press.

Ministry of Education and Training [MOET] (2006). Chuong trinh giao duc pho thong: Mon tieng Anh [English curriculum for the secondary school]. Hanoi, Vietnam: Education Publishing House.

Morrison, D. E. (1998). The search for a method: Focus groups and the development of mass communication research. Luton, England: University of Luton Press.

Murray, G. (2009). Narrative inquiry. In J. Heigham \& R. A. Croker (Eds.), Qualitative research in applied linguistics: A practical introduction (pp.45-65). Basingstoke, England: Palgrave Macmillan.

National Institute of Education (1975). Teaching as clinical information processing: Report of Panel 6 [microform]. National Conference on Studies in Teaching. Washington, DC: National Institute of Education.

Nishino, T., \& Watanabe, M. (2008). Communication-oriented policies versus classroom realities in Japan. TESOL Quarterly, 42(1), 133-138.

Nonkukhetkhong, K., Baldauf, R., Jr., \& Moni, K. (2006). Learner-centredness in teaching English as a foreign language: Teachers' voices. Paper presented at 26 Thai TESOL International Conference, Chiang Mai, Thailand.

Nunan, D. (2003). The impact of English as a global language on educational policies and practices in the Asia-Pacific region. TESOL Quarterly, 37(4), 589-613.

Nunan, D. (2004). Task-based language teaching. Cambridge, England: Cambridge University Press. 
Pavlenko, A. (2007). Autobiographic narratives as data in applied linguistics. Applied Linguistics, 28(2), 163-188. http://dx.doi.org/10.1093/applin/amm008

Pham, H. H. (2000). Traditional versus modern teaching methods. Teacher's Edition, 2, 20-23.

Polkinghorne, D. E. (1995). Narrative configuration in qualitative analysis. Qualitative Studies in Education, 8(1), 5-23. http://dx.doi.org/10.1080/0951839950080103

Sato, K. (2002). Practical understandings of communicative language teaching and teacher development. In S. Savignon (Ed.), Interpreting communicative language teaching: Contents and concerns in teacher education (pp. 41-81). New Haven, CT: Yale University Press.

Segovia, L. P. D., \& Hardison, D. (2009). Implementing education reform: EFL teachers' perspectives. ELT Journal, 63(2), 154-162. http://dx.doi.org/10.1093/elt/ccn024

Tayjasanant, C., \& Barnard, R. (2010). Language teachers' beliefs and practices regarding the appropriateness of communicative methodology: A case study from Thailand. Journal of Asia TEFL, 7(2), 277-311.

Tomlinson, B., \& Bao, D. (2004). The contributions of Vietnamese learners of English to EFL methodology. Language Teaching Research, 8(2), 199-222. http://dx.doi.org/10.1191/1362168804Ir140oa

Van, H. V., Hoa, H. T. X., Loc, D. N., Loi, V. T., Minh, D. T., \& Tuan, N. Q. (2006). Tieng Anh 10, Teacher's book. Hanoi, Vietnam: Education Publishing House.

Wang, H. (2008). Language policy implementation: A look at teachers' perceptions. Asian EFL Journal Professional Teaching Articles,30. Retrieved from http://www.asian-efl-journal.com/pta_August_08.pdf

Warwick, P. \& Maloch, B. (2003). Scaffolding speech and writing in the primary classroom: A consideration of work with literature and science pupil groups in the USA and UK. Reading, 37(2), 54-63. http://dx.doi.org/10.1111/1467-9345.3702003

Wray, D. \& Lewis, M. (1997). Extending literacy: Children reading and writing non-fiction. London, England: Routledge.

Yoon, K. (2004). CLT theories and practices in EFL curricula: A case study of Korea. Asian EFL Journal, 6(3). Retrieved from http://www.asian-efl-journal.com/september_04_yke.php 